\title{
Book Review: Culturally Inclusive Instructional Design: A Framework and Guide to Building Online Wisdom Communities
}

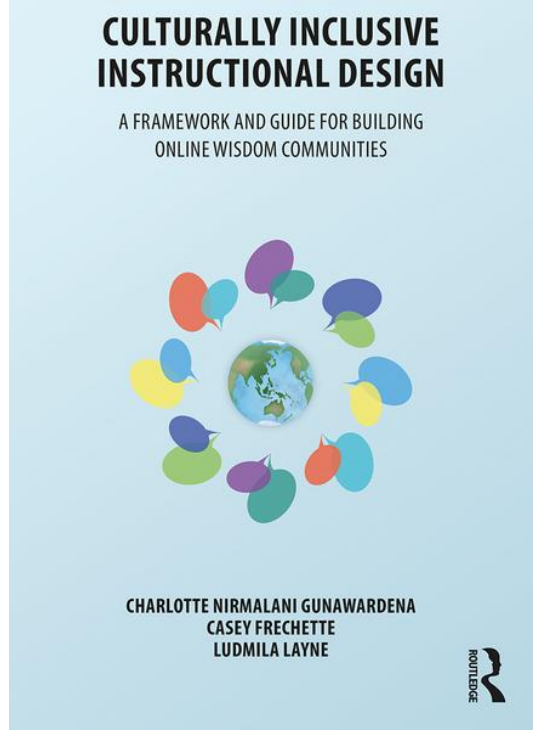

Authors: Charlotte Gunawardena, Casey Frechette, and Ludmila Layne: ( NY: Routledge, 2019, 286 pages) ISBN: 978-1-138-21786-7

Reviewed by: Gülten Kartal, PhD Student, Anadolu University, Turkey

Written by Charlotte Gunawardena, Casey Frechette, and Ludmila Layne, and contributed to by Damien M. Sanchez and Linda Barril, this book explores the WisCom instructional design model that aims to create and maintain a culturally inclusive wisdom community in online learning environments. The model mainly consists of seven components: wisdom community, communication, technology, distributed co-mentoring, learner support, the collaborative inquiry cycle, and transformative learning. The details of all the components related to the model, the learning theories that the model relies on, and other related issues such as the development, implementation, assessment, research, and evaluation processes, are discussed. Accordingly, the explanations are divided into four sections. In the first section, some theoretical foundations of the WisCom model and the culture and wisdom concepts of the model, are discussed comprehensively. In the second section, the WisCom model and its seven components are explained in detail. Comprehensive descriptions of the assessment and evaluation methods of the WisCom model are presented to the reader in the third section, including the presentation of a variety of methods, techniques, and research examples about learning in the wisdom community. The final section covers topics such as the needs analysis, learner assessment and evaluation, design and development to create online wisdom communities among cultures, and the development of this model.

Considering the $21^{\text {st }}$ century skills required in the network society, the book offers a new instructional design model for learning in online environments where cultural diversity is an indispensable element. In this way, it is a flexible model that covers the current situation and meets future needs and therefore is able to meet and develop important features. At the same time, the model adds diversity to existing 
instructional design models as it can be applied not only in online environments but also in face-to-face learning environments. Besides this, it is evident that the model is open to further development by applying it in different cultures and environments. There are different books in the field of open and distributed learning that refer to cultural diversity in online learning environments; however, many of these books address points under different categories. In this book, the integrity of the chapters has been captured; messages and important issues are clearly expressed to explain the instructional design model. The book inspires new research on dimensions such as analysis and evaluation of the WisCom framework.

The 2017 Horizon Report emphasizes the importance of enhancing cultures of innovation, collaborative learning, and digital literacy (Adams Becker et al., 2017); and the 2018 Horizon Report, it highlights the importance of cross-institutional and cross-sectoral collaboration and authentic learning experiences (Adams Becker et al., 2018). Covering the pandemic and post-pandemic period, the 2020 and 2021 Horizon reports also draw attention to the consideration of diversity and support equity and inclusion in education due to the increase in the online globalization and student population (Brown et al., 2020; Pelletier et al., 2021). The components and perspectives of WisCom instructional design shaped 18 years ago (pp. xvi) covers the current and future issues in line with current reports, making this a forwardlooking, comprehensive, and versatile perspective.

The organization of the book is very well-structured yet the chapter on regulation transformative learning (Chapter 10) could have been placed after the concepts of wisdom and wisdom communities that were elaborated on in Chapters 3 and 4. In addition, new tools and methods could have been developed to contribute to the WisCom framework, supported by a system for matching the mentors with mentees or co-mentors communities. As such, the learning outcomes of the course could be categorized before teaching and learning starts. The skill and competency level, according to the collaboration and knowledge level of each learner, could then be taken as data, which would show the learner's existing knowledge and situation. In other words, some learner's existing knowledge could be potential knowledge that another learner could reach at the end of learning. In this view, some learners that have collaboration skills and knowledge could be the best mentors for other learners. Accordingly, the best mentor-mentee or co-mentors matching system could be developed through the use of different algorithms. This might help to improve the transformative learning potential of the environment in the best way, because in the transformative learning environment, the learner has the potential knowledge and helps to improve existing knowledge of other learners. As well, it could help to determine the zone of proximal development of learners besides revealing the transformative learning needs assessment. In this way, the model contributes to the transformative learning needs assessment component of the WisCom Needs Assessment.

In summary, the WisCom model is a very important contribution to open and distributed learning. This book is a helpful guide and a fundamental reference that provides knowledge and new perspectives to researchers, instructional designers, specialists, and practitioners interested in the fields of distance education, learning, and culture. 


\section{References}

Adams Becker, S., Brown, M., Dahlstrom, E., Davis, A., DePaul, K., Diaz, V., \& Pomerantz, J. (2018). NMC Horizon Report: 2018 Higher Education Edition. EDUCAUSE. https://library.educause.edu/ /media/files/library/2018/8/2018horizonreport.pdf

Adams Becker, S., Cummins, M., Davis, A., Freeman, A., Hall Giesinger, C., \& Ananthanarayanan, V. (2017). NMC Horizon Report: 2017 Higher Education Edition. The New Media Consortium. https://library.educause.edu/-/media/files/library/2017/2/2017horizonreporthe.pdf

Brown, M., McCormack, M., Reeves, J., Brooks, D. C., \& Grajek, S., with Alexander, B., Bali, M., Bulger, S., Dark, S., Engelbert, N., Gannon, K., Gauthier, A., Gibson, D., Gibson, R., Lundin, B., Veletsianos, G., \& Weber, N. (2020). EDUCAUSE Horizon Report, Teaching and Learning Edition. EDUCAUSE. https://library.educause.edu/$\lfloor$ media/files/library/2020/3/2020 horizon report pdf.pdf?la=en\&hash=08A92C17998E81 13BCB15DCA7BA1F467F303BA80

Pelletier, K., Brown, M., Brooks, D. C., McCormack, M., Reeves, J. \& Arbino, N., with Bozkurt, A., Crawford, S., Czerniewicz, L., Gibson, R., Linder, K., Mason, J., \& Mondelli, V. (2021). EDUCAUSE Horizon Report, Teaching and Learning Edition. EDUCAUSE. https://library.educause.edu/Lmedia/files/library/2021/4/2021hrteachinglearning.pdf?la=en\&hash=C9DEC12398593F29 ZCC634409DFF4B8C5A60B36E

\section{Athabasca}

University

(c) (i) 